Families in Transition: The Impact of Family Relationships and Work on Mobility Patterns of Aboriginal People Living in Urban Centres across Canada

Jacqueline Quinless

PhD Candidate, Department of Sociology, University of Victoria

Ricardo Manmohan

PhD Candidate, Interdisciplinary Studies, Royal Roads University

aboriginal policy studies Vol. 5, no. 2, 2016, pp. 114-135

This article can be found at:

http://ejournals.library.ualberta.ca/index.php/aps/article/view/25351

ISSN: $1923-3299$

Article DOI: http://dx.doi.org/10.5663/aps.v5i2.25351

aboriginal policy studies is an online, peer-reviewed and multidisciplinary journal that publishes original, scholarly, and policy-relevant research on issues relevant to Métis, non-status Indians and urban Aboriginal people in Canada. For more information, please contact us at apsjournal@ualberta.ca or visit our website at www.nativestudies.ualberta.ca/research/aboriginal-policy-studies-aps. 


\section{Families in Transition: The Impact of Family Relationships and Work on Mobility Patterns of Aboriginal People Living in Urban Centres across Canada}

Jacqueline Quinless

PhD Candidate, Department of Sociology, University of Victoria

Ricardo Manmohan

PhD Candidate, Interdisciplinary Studies, Royal Roads University

Abstract: The present analysis makes use of data taken from the public use micro data file (PUMF) from the 2012 Aboriginal Peoples Survey (APS) to examine the effects of various socioeconomic factors such as age, sex, education level, family composition (expressed by the number of children in the household), and total personal income on the mobility patterns of Aboriginal people living off-reserve across Canada. Two separate path analyses were conducted to evaluate critically the decomposition effects that these variables have on mobility. The results of the path analysis show that age is inversely related to mobility, meaning younger people move more frequently. However, contrary to other studies, this research analysis shows that age becomes less significant when we consider that people with higher levels of education are indeed more mobile than others, although the strength of this effect is actually mediated through personal income and family composition.

\section{Introduction}

Since 1996 the Aboriginal population in Canada has grown by forty-five percent, nearly six times faster than the eight-percent rate increase for the non-Aboriginal population, and in 2011, 1.4 million people self- identified as Aboriginal in Canada. Today a substantial proportion (fifty-seven percent) of Aboriginal people, a relatively young and growing population, reside in major urban centres across Canada (Statistics Canada 2015). There has also been an increasing trend in the incidence of lone-parent families in the Aboriginal community, particularly among First Nations (Hull 2006). Previous research has shown that highly mobile households tend to be headed by single Aboriginal women with a need for affordable rental accommodation that often leads these families to search for homes in inner city neighbourhoods characterized by lower housing costs (Mochama 2001). This trend towards urbanization has led to a substantial increase in the urban Aboriginal lone-parent family population in recent years in metropolitan areas such as Winnipeg, Edmonton, Regina, Saskatoon, and Vancouver (Siggner and Costa 2005). Further research into the area of Aboriginal lone-parent families shows that the number of such families living in poverty is high when compared to non-Aboriginal lone-parent and coupled families. More importantly, the degree of poverty and associated substandard living conditions often experienced by long-parent families tend to differ when we further 
consider other socioeconomic factors of these lone-parent families such as such as age and gender of the parent, number of children living in the household, the parent's educational attainment, and place of residence (Newhouse and Peters 2001; Willa, Yuen, Engeland, and Figueroa 2008).

But what are the reasons for the lone parenting? The pathways to Aboriginal lone parenthood are not linear and often include a complex system of interrelated factors such as widowhood, separation, divorce or childbirth outside marriage, as well as the changing dynamic of an individual's family status over time (Quinless 2013). High fertility rates among Aboriginal women have often been cited as one of the main factors contributing to lone parenting. For example, since 1986, the fertility rates of Aboriginal teenage girls under 20 years of age have remained high when compared to the rates of other Canadian teenagers. One study has shown that the fertility rate for First Nations girls under the age of 15 is estimated to be approximately 18 times higher than that of other Canadians (Guimond and Robitaille 2008).

The decision to move is not based on a single factor, but rather on a number of intervening and latent variables. Almost twenty-five years ago, research using 1991's Aboriginal Peoples Survey (APS) data found "family and housing" to be key factors for moving in general. Education was identified as the main factor in the decision to leave a First Nations community and move to urban areas, whereas movement from one urban centre to another was most often initiated as the result of a search for employment (Clatworthy and Norris 2007). An individual's stage in life (marked by milestones like getting married or buying a home, for example) and personal attributes (gender, level of education, or number of children in the household) have been found to have an impact on mobility patterns. There are also macro-level community factors that influence the decision to move, such as access to schools, employment, and healthcare services (Clatworthy and Norris 2007). The present analysis makes use of data taken from the 2012 Aboriginal Peoples Survey public use micro data file (PUMF) specifically to examine the intervening effects of various socioeconomic factors such as age, sex, education level, family composition-expressed by the number of children in the household-and income on the mobility patterns of Aboriginal people living off-reserve across Canada. The paper begins with an overview of the general trends in mobility patterns of Aboriginal people since 1996 to contextualize the main factors that affect high mobility levels. The paper then provides a discussion of the effects of the main demographic and socioeconomic factors on mobility observed from the path analysis results.

\section{Literature Review}

\section{Mobility Patterns of Aboriginal People}

A variety of factors affect the mobility patterns of Aboriginal people in Canada, including age, income level, employment, and identity group. The study by Norris and Clatworthy (2007) found that females aged twenty to twenty-four years had higher rates of mobility away 
from reserves compared to men in the same age group. Moreover, higher overall mobility rates between urban centres and reserves were observed among young adult females with children, slightly more so for females who were Registered Indians as compared to nonStatus females (Norris et al. 2003; Norris and Clatworthy 2007).

Many studies have identified that a considerable percentage of Aboriginal women in large urban centres who moved there from reserves are lone parents. Aboriginal women tend to move for family related reasons, which is reflected by a search for better social services, improved healthcare, and educational opportunities that will help them and their children; in contrast, Aboriginal men tend to report economic factors as primary motivations for migrating (Maxim, Keane, and White 2003; Newhouse and Peters 2003). Aboriginal families residing off-reserve are more likely than other Canadian households to be headed by a female lone parent, to tend to live in cities and towns, and to be in need of core housing (Canadian Mortgage and Housing Corporation 1997).

A vast majority of the research on Aboriginal people's mobility patterns tends to focus on mobility patterns between communities, i.e., on- and off-reserve (Siggner and Costa 2005; Hull 2006; Quinless 2009). While this is important, there is also a need to understand the issues surrounding mobility patterns and changing residences within the same community, i.e., within a particular city or neighbourhood. This last dimension of mobility is important to understand because it constitutes a significant process through which a lone-parent household adjusts and often readjusts its housing situation in response to changes in needs and resources (Clatworthy 2008).

Previous research has shown that high-mobility patterns exist among Aboriginal people and particularly lone-parent families who reside in urban centres. This in turn, can create significant barriers to program and service delivery, posing challenges in reaching, maintaining contact with, and delivering housing, healthcare, social services, training, and education to Aboriginal families (Clatworthy 2008; Siggner and Costa 2005; Hull 2006; Quinless 2009). According to the Caledon Institute of Social Policy, thirty percent of those people who self-identified as Aboriginal in Winnipeg had changed addresses at least once prior to the 2001 Census; of this thirty percent, about seven percent came from a different Census subdivision (Mendelson 2004). A similar report focusing on recent arrivals to Winnipeg noted that mobility remained high even after members of households arrived in the city. Approximately 400 recently arrived households were surveyed three times, with the surveys four months apart. Between the first and second surveys, thirty-one percent of households moved once, fifty-eight percent moved twice, and eleven percent moved three times. Between the second and third surveys, seventy-seven percent moved once, twenty percent moved twice, and three percent moved three times (Institute of Urban Studies 2004). This indicates that even after arriving in the city, Aboriginal people's residential mobility remains high, suggesting that this group remains in frequent transition within the city of Winnipeg.

The fact that Aboriginal people relocate more frequently than other Canadians is indicative that their needs are not being addressed in terms of housing costs, education, 
employment opportunities, and childcare, and suggests that vital programs and services are not present or are not being effectively delivered to them. The social implications of frequent mobility in urban areas result in high population turnover, in addition to disruptive effects on individuals, families, communities, and services providers. The incidence of high mobility and its effect on Aboriginal families have far-reaching social policy implications in relation to adequate program and service delivery in the areas of education, health, employment, and child care. For example, a recent study using data from Statistics Canada's 2006 Aboriginal Peoples Survey demonstrates that mobility is significantly correlated to the use of health service within urban settings. The findings of this study showed that urban newcomers were more likely to visit a physician or nurse compared to long-term residents, indicating that traditional healing may represent an unmet healthcare need. The results of this study suggest that Aboriginal mobility patterns and understanding the reasons for the high rates of mobility have important implications for how health services are planned and delivered to urban Aboriginal people (Snyder et al. 2012).

\section{Key Factors that Affect Mobility}

The reasons for high mobility rates among Aboriginal peoples are well-documented in the literature (Norris and Clatworthy 2003; Norris and Siggner 2003; Hull 2006; Quinless 2009), and are connected to the impact of colonialism and its social manifestations of systemic racism, prejudice, and discrimination. This gives rise to other key factors that have been credited with Aboriginal people's frequent moves, including the impact of family violence (Quinless 2009), and the search for employment opportunities, adequate housing, health services, training, and education (Norris and Clatworthy 2003; Norris and Siggner 2003; Hull 2006; Institute of Urban Studies 2004). Certainly, all of these socioeconomic factors are linked to the legacy and impact of colonialism. The history of forced mobility in the form of residential schooling and the "Sixties Scoop," in which Aboriginal children were taken from their families and placed with white families, fractured communities (Ristock 2010). Although some communities were more affected than others, the resultant loss of identity and disconnection from traditional Aboriginal culture continue to have a devastating impact on many communities and their members (Ristock 2010).

One of the main driving forces related to high mobility is access to affordable housing. Housing is considered to be a serious problem for many Aboriginal people, who tend to spend a higher proportion of their earnings on housing than those in the non-Aboriginal population (Palmer 2007). The difficulties associated with obtaining and remaining satisfied with housing are related to housing affordability, adequacy, and quality (Royal Commission on Aboriginal Peoples 1993). While Aboriginal people may choose to move to urban areas in search of jobs and better housing, they often end up living in poor-quality, unaffordable housing in declining inner-city neighbourhoods. A shortage of housing, discrimination by landlords, lack of information on housing availability, inadequate/ substandard housing, and unaffordable costs then contribute to increased mobility patterns for Aboriginal people even after they have arrived in the city. Previous studies 
(Norris and Clatworthy 2003; Norris and Siggner 2003; Hull 2006; Institute of Urban Studies 2004) have shown that housing shortages or poor-quality housing are particular problems for Aboriginal elders, lone-parent families, homeless people, and students. Their low income, lack of savings, and lack of financial support, as well as the general lack of homebuying initiatives and low-income rental housing available to them contribute to housing problems. Extremely high proportions of Aboriginal lone-parent households are in need of basic housing. In urban Manitoba, Saskatchewan, and British Columbia, where most Aboriginal lone-parent households are located, core housing need affects more than seven out of ten households overall, and eight in ten of those renting (Spector 1997).

While the Aboriginal population on the whole tends to be a highly mobile group, it is important to recognize that there are significant demographic and socioeconomic differences among residential movers, with consequent different needs and services for each of these groups. For example, Aboriginal people with high mobility rates, who represent about twenty percent of the urban population of Canada's larger cities, tend to be younger, are often lone-parent families, and have fewer children (Norris and Clatworthy 2003). Meanwhile, Aboriginal people who move to large urban areas from more remote reserves may face greater challenges, as there may be a significant gap between their cultural and educational experiences and urban realities (Chalifoux and Johnson 2003) and may have more difficulty adapting to urban life.

Despite the fact that the Aboriginal population in urban centres has been growing, this does not appear to be contributing to a significant decline in the population of on-reserve Aboriginal communities. Instead, factors such as "high birth rates, ethnic mobility (i.e., changes to self-reporting of ethnic affiliations), and legislative changes" (Ning 2013, 1) serve to maintain the population and, in some cases, can also lead to population growth (Snyder and Wilson 2012). Statistics suggest that mobility rates of Aboriginal youth are high due to the limited education and employment opportunities available on-reserve. Key factors pulling young Aboriginal people to urban centres are the search for employment and higher levels of education (Ning 2013). For example, there is a seasonal flow of Aboriginal workers into and out of urban areas; during the winter, these people move to urban areas for employment, and in the summer they return home to their families on-reserve (Aman 2008).

Education level in combination with family composition (expressed by the number of children in a household) and income, in addition to various social and economic factors, affect Aboriginal mobility patterns. Previous research studies have suggested that the decision to move is not based on a single factor, but rather that there are a number of intervening and latent variables involved in the decision to move. For example, Clatworthy et al. (2007) found that "family and housing" were key factors in decisions to move in general, but education was identified as the main driver in the decision to leave a reserve and move to an urban area. An individual's stage in life (involving milestones such as getting married or buying a home) and personal attributes (gender, level of education, or number of children in the household) have also been found to influence mobility patterns (Clatworthy and Norris 2007). Based on the literature review outlined here, the following hypotheses have been used to guide the analytical component of this paper. 


\section{Hypotheses}

$\mathbf{H}_{1}$ : It is proposed that age will be inversely related to an individual's level of mobility. Specifically, it is proposed that a person who is older will move less frequently when compared to someone who is younger. Based on previous research, it has been demonstrated that age is a strong predictor of mobility due to the life-stage changes that occur as people get older. Most mobility-triggering events occur in younger age groups, and with the "much younger age structure of the Aboriginal population, one would expect residential mobility to be more common among Aboriginal peoples" (Clatworthy and Norris 2007).

$\mathbf{H}_{2}$ : It is proposed that higher levels of income will inversely affect an individual's mobility. This means that a person with a higher income will not move as often as someone with a lower income. Research has shown that employment and income level are important predictors in determining the likelihood that a person will move. The inability to find viable employment can be challenging in Aboriginal communities, and this can create a significant push away from rural areas.

$\mathbf{H}_{3}$ : It is proposed that higher levels of education will be positively related to an individual's level of mobility. Seeking higher levels of education tends to push people away from rural communities into larger urban centres where post-secondary education can be pursued. This was cited as the main factor in the decision to leave an Aboriginal community (Clatworthy and Norris 2007; Quinless 2013; Clatworthy 1996).

$\mathbf{H}_{4}$ : It is proposed that females will move more frequently than males. This hypothesis is based on the number of single women raising children in Aboriginal communities. A study by Norris and Clatworthy (2007) found that females aged twenty to twenty-four years had higher rates of mobility away from reserves compared to men in the same age group. Moreover, higher overall migration rates from urban centres back to reserves were observed among young adult females with children, slightly more so for females who were Registered Indians as compared to non-Status females (Norris et al. 2003; Norris and Clatworthy 2007).

$\mathbf{H}_{5}$ : It is proposed that having children within a household is a significant predictor of mobility. Specifically, rural areas' lack of services normally associated with families with children (i.e., health, dental, and extracurricular) would result in these families moving to more urban centres where services are more readily available.

\section{Data and Methods}

\section{Sample}

The data used in this analysis were drawn from weighted data of the 2012 Aboriginal Peoples Survey PUMF (adults). The APS collects social and economic data from Aboriginal individuals living off-reserve. Developed in collaboration with Aboriginal organizations, the APS is conducted every five years. The target population of the 2012 APS was composed of the Aboriginal identity population of Canada aged six years and over as of February 1, 2012, 
living in private dwellings, excluding people living on Indian reserves and settlements and in certain First Nations communities in Yukon and the Northwest Territories (NWT). ${ }^{1}$ The sample was selected from individuals who answered "yes" to any one of the three National Household Survey (NHS) questions defining the identity population (questions 18, 20, and 21), or those who reported Aboriginal ancestry on question 17 (Statistics Canada 2012). Individuals with Aboriginal ancestry who did not report Aboriginal identity are defined as the "Aboriginal ancestry-only population." Based on changes in the survey methodology of the 2006 Census 2B Long Form and the 2006 APS, the ancestry-only population was not part of the 2012 APS target population. However, Statistics Canada affirms that this population was sampled nonetheless because slightly less than one-third of the ancestryonly population based on the 2006 Census long form reported identity on the 2006 APS. Therefore, unlike the target population, the sampled population was composed of both the identity population and the Aboriginal ancestry-only population, which together form the "total Aboriginal population" in Canada (Cloutier et al. 2014).

Using a cross-sectional design, the sample survey consisted of approximately 28,410 Aboriginal individuals and achieved a response rate of seventy-six percent. ${ }^{2}$ For this analysis we have used only data from individuals who self-identify as First Nations, Metis, Inuit, or a combination of Aboriginal backgrounds, and we have omitted missing data. This reduces the sample to $\mathrm{N}=24,803$. The content for the 2012 APS was developed by Statistics Canada in collaboration with the three federal funding departments: Aboriginal Affairs and Northern Development Canada, Health Canada, and Employment and Social Development Canada (formerly called Human Resources and Skills Development Canada). In addition, the framework guiding content development was produced by the Canadian Council on Learning (CCL) in partnership with First Nations, Inuit, and Metis communities and organizations across Canada (Cloutier et al. 2014). The 2012 APS provides detailed data on education, employment, and health unique to urban Aboriginal people. The survey addresses topics such as number of schools attended, exposure to Aboriginal languages, traditional activities, peer influences, and plans for further schooling. The primary objective of the 2012 APS is to provide data on the social and economic conditions of Aboriginal people in Canada. More specifically, it focuses on issues such as health, language, employment, income, schooling, housing and mobility.

1 The concept of "Aboriginal identity" refers to those persons who reported identifying with at least one Aboriginal group, namely, First Nations (North American Indian), Métis, or Inuit; those who reported being a Status Indian (Registered Indian or Treaty Indian, as defined by the Indian Act of Canada); or those who reported being a member of a First Nation or Indian band.

2 The 2012 APS sample was designed to provide reliable estimates for certain combinations of geographic regions, Aboriginal groups, and education groups. These groups of units for which estimates are targeted are called "domains of estimation." For confidentiality reasons, the domains of estimation used in the sample design had to be modified for the PUMF. Person-weights were created for the survey, with one person-weight associated with each survey respondent. These weights reflect an unequal probability of selection for the sampled units as well as several adjustment factors that were applied to the sampling weights for such things as non-response and post-stratification (weights adjusted to NHS estimates) (Cloutier et al. 2014). 


\section{Measures}

\section{Outcome Variable}

Mobility (M1): The outcome variable (mobility) was created by combining eight mobility questions from the 2012 APS that measure the factors involved in the decision to move. The dichotomous response for each of these questions is $1=$ yes or $2=$ no, and the sample size is the same for each of these questions (n-12,587). At times, respondents selected "yes" for more than one of the eight questions (i.e., moved for both family/spouse and employment). The 2012 APS mobility variables of "moved for family/spouse" and "moved for employment" are considered in this analysis, leading to the creation of two path analyses. They were chosen as they are the most frequently identified reason for making the decision to move.

\section{Predictor Variables}

Age (A1): The age of respondents was originally broken down into nine categories beginning at six years of age: $1=$ ages $6-8 ; 2=$ ages $9-11 ; 3=$ ages $12-14 ; 4=$ ages $15-18 ; 5=$ ages $19-24 ; 6=$ ages $25-34 ; 7=$ ages $35-44 ; 8=$ ages $45-54$; and $9=$ ages $55+$. This continuous ordinal data was then collapsed into categories for analysis.

Sex (S1): Sex was originally coded as $1=$ male and $2=$ female. Female was recoded to 0 in this dichotomous variable. A total of 12,814 females and 11,989 males responded to the questionnaire.

Education (E1): The continuous ordinal variable regarding the "highest level of education attained" was recoded to collapse "grade eight or equivalent or lower" with "some secondary education." The variable distribution for this question was based on the following distribution: Secondary not completed; Secondary completed; Some postsecondary; Diploma completed; Bachelor Completed.

Income (I1): Income is a measure of total personal income. For the purpose of this analysis, this variable was recoded and treated as a continuous variable.

Number of Children (C1): There were two choices of variables from the 2012 APS data to determine the number of children in a family: number of children, and household composition. The number-of-children variable was drawn only from females and referred only to the children they had "given birth to." We acknowledge the community approach and role of extended family in raising children to be an integral component of Aboriginal culture, and thus used household composition, since it is a culturally responsive measure to number of children within the "family." This variable remained the same as it was initially coded, and was separated into three nominal variables: $1=$ couple with children; $2=$ couple without children; and $3=$ lone parent with children. 


\section{Model Specification}

The 2012 APS mobility variables of "moved for family/spouse" and "moved for employment" were considered in this analysis, leading to the creation of two path analyses. These two variables were selected for the analysis based on the frequency with which they were identified as the main reasons for moving. This study employed a path analysis using Ordinary Least Squares (OLS) regression to examine the causal relationship among age, sex, income level, educational level, and household composition and their effect on mobility patterns of Aboriginal people living "off-reserve." Two separate path analyses were employed here, since this analytical approach accounts for intervening effects between household composition and income level.

\section{Results}

The Pearson correlation ( $\mathrm{r}$ ) was used in this analysis to determine the correlation between the dependent variable of "moved for family/spouse" and the independent variables of age, sex, education level, number of children in the household, and income distribution (see Table 1). Table 1 reveals that almost all of the scores are significant to an alpha level of 0.01 and that the highest positive correlation exists between income level and education level, with a weak positive correlation between income level and moving for family/spouse.

The Pearson correlation ( $r$ ) was also used to determine the correlation between the dependent variable of 'moved for work' and the same independent variables of age, sex, education level, number of children in the household and income distribution. The results are shown in Table 2 below. Again, we see that almost all of the scores are significant to an alpha level of 0.01 . Here as well, most of the scores show a weak to negligible correlation. The majority of correlations in this analysis are negative; however, the highest correlation was a positive one between income level and education level.

\section{Path Analysis Results}

Separate path analyses were conducted for both mobility reasons- "moved for family/ spouse" and "moved for work"-in order to examine causal relationships among these six variables. These relationships are indicated by the path coefficients below, and "show the effect of the independent on the dependent variables and also any relationship between independent variables" (Foster et al. 2006, 89). This approach to analysis was selected due to the complexity of mobility, and it enables us to identify correlations between independent/ predictor variables (Foster et al. 2006, 90). It also allows us to examine the causal effects of various predictor variables on an outcome variable. In this case, the predictor variables (Xs) are age, sex, level of education, children in household, and level of income. Of these, the exogenous variables are age, sex, and level of education (Model 1A in appendix). The outcome variable $(\mathrm{Y})$ in the first path analysis is "moved for family/spouse" (Figure 1); "moved for work" (Figure 2) is the outcome variable in the second. The remaining two variables (children in household and level of income) are intervening variables that cause 
indirect effects on the outcome variable (Foster et al. 2006). These were calculated separately and can be seen in Model 1B (children) and Model 1C (income) in the appendix. Model $3 \mathrm{~A}$ in the appendix shows the relationship between income and the number of children in the household.

TABLE 1: Moved for Family/Spouse Correlations

\begin{tabular}{|c|c|c|c|c|c|c|c|}
\hline & & $\begin{array}{c}\text { Moved for } \\
\text { Family/Spouse }\end{array}$ & $\begin{array}{c}\text { Age } \\
\text { Recoded }\end{array}$ & $\begin{array}{c}\text { Sex } \\
\text { Recoded }\end{array}$ & $\begin{array}{c}\text { Education } \\
\text { level }\end{array}$ & $\begin{array}{c}\text { Household } \\
\text { Children }\end{array}$ & $\begin{array}{c}\text { Income } \\
\text { Distribution }\end{array}$ \\
\hline $\begin{array}{l}\text { Moved for } \\
\text { Family/Spouse }\end{array}$ & $\begin{array}{l}\text { Pearson's r } \\
\text { Sig. (2- } \\
\text { tailed) } \\
\mathrm{N}\end{array}$ & 12587 & & & & & \\
\hline Age Recoded & $\begin{array}{l}\text { Pearson's r } \\
\text { Sig. (2- } \\
\text { tailed) } \\
\mathrm{N}\end{array}$ & $\begin{array}{r}.163^{* \star} \\
.000 \\
10291 \\
\end{array}$ & $\begin{array}{r}1 \\
18135 \\
\end{array}$ & & & & \\
\hline Sex Recoded & $\begin{array}{l}\text { Pearson's r } \\
\text { Sig. (2- } \\
\text { tailed) } \\
\mathrm{N}\end{array}$ & $\begin{array}{r}.040^{* \star} \\
.000 \\
12587 \\
\end{array}$ & $\begin{array}{r}-.030^{* *} \\
.000 \\
18135 \\
\end{array}$ & $\begin{array}{r}1 \\
24803 \\
\end{array}$ & & & \\
\hline $\begin{array}{l}\text { Highest } \\
\text { education level } \\
\text { attained }\end{array}$ & $\begin{array}{l}\text { Pearson's r } \\
\text { Sig. (2- } \\
\text { tailed) } \\
\mathrm{N}\end{array}$ & $\begin{array}{l}.097^{* *} \\
.000 \\
.0097 \\
\end{array}$ & $\begin{array}{r}.000 \\
.956 \\
15253 \\
\end{array}$ & $\begin{array}{r}-.082^{* *} \\
.000 \\
15308 \\
\end{array}$ & $\begin{array}{r}1 \\
15308 \\
\end{array}$ & & \\
\hline $\begin{array}{l}\text { Household } \\
\text { Children }\end{array}$ & $\begin{array}{l}\text { Pearson's r } \\
\text { Sig. (2- } \\
\text { tailed) } \\
\mathrm{N}\end{array}$ & $\begin{array}{r}-.056^{* \star} \\
.000 \\
10199 \\
\end{array}$ & $\begin{array}{r}.020^{*} \\
.013 \\
14801 \\
\end{array}$ & $\begin{array}{r}-.052^{* *} \\
.000 \\
20684 \\
\end{array}$ & $\begin{array}{r}-.098^{* *} \\
.000 \\
12333 \\
\end{array}$ & $\begin{array}{r}1 \\
20684 \\
\end{array}$ & \\
\hline $\begin{array}{l}\text { Income } \\
\text { Distribution }\end{array}$ & $\begin{array}{l}\text { Pearson's r } \\
\text { Sig. (2- } \\
\text { tailed) } \\
\mathrm{N}\end{array}$ & $\begin{array}{l}.203^{* *} \\
.000 \\
9513\end{array}$ & $\begin{array}{r}.309^{* \star} \\
.000 \\
16593 \\
\end{array}$ & $\begin{array}{r}.159^{* \star} \\
.000 \\
16593\end{array}$ & $\begin{array}{r}.335^{* *} \\
.000 \\
14049 \\
\end{array}$ & $\begin{array}{r}-.124^{* *} \\
.000 \\
13646 \\
\end{array}$ & $\begin{array}{r}1 \\
16593 \\
\end{array}$ \\
\hline
\end{tabular}

**. Correlation is significant at the 0.01 level (2-tailed).

*. Correlation is significant at the 0.05 level (2-tailed). 
TABLE 2: Moved for Work - Correlations

\begin{tabular}{|c|c|c|c|c|c|c|c|}
\hline & & $\begin{array}{c}\text { Moved } \\
\text { for } \\
\text { Work }\end{array}$ & $\begin{array}{c}\text { Age } \\
\text { Recoded }\end{array}$ & $\begin{array}{c}\text { Sex } \\
\text { Recoded }\end{array}$ & $\begin{array}{c}\text { Education } \\
\text { Level }\end{array}$ & $\begin{array}{c}\text { Household } \\
\text { Children }\end{array}$ & \begin{tabular}{|c} 
Income \\
Distribution
\end{tabular} \\
\hline $\begin{array}{l}\text { Moved for } \\
\text { Work }\end{array}$ & $\begin{array}{l}\text { Pearson's r } \\
\text { Sig. (2- } \\
\text { tailed) } \\
\text { N }\end{array}$ & $\begin{array}{r}1 \\
12587\end{array}$ & & & & & \\
\hline Age Recoded & $\begin{array}{l}\text { Pearson's r } \\
\text { Sig. (2- } \\
\text { tailed) } \\
\mathrm{N} \\
\end{array}$ & $\begin{array}{r}-.145^{* \star} \\
.000 \\
10291 \\
\end{array}$ & 18135 & & & & \\
\hline Sex Recoded & $\begin{array}{l}\text { Pearson's r } \\
\text { Sig. (2- } \\
\text { tailed) } \\
\text { N }\end{array}$ & $\begin{array}{r}-.109^{* *} \\
.000 \\
12587\end{array}$ & $\begin{array}{r}-.030^{* *} \\
.000 \\
18135\end{array}$ & 1 & & & \\
\hline $\begin{array}{l}\text { Highest } \\
\text { education } \\
\text { level attained }\end{array}$ & $\begin{array}{l}\text { Pearson's r } \\
\text { Sig. (2- } \\
\text { tailed) } \\
\text { N }\end{array}$ & $\begin{array}{r}-.116^{* *} \\
.000 \\
9097 \\
\end{array}$ & $\begin{array}{r}.000 \\
.956 \\
15253 \\
\end{array}$ & $\begin{array}{r}-.082^{* *} \\
.000 \\
15308 \\
\end{array}$ & $\begin{array}{r}1 \\
15308 \\
\end{array}$ & & \\
\hline $\begin{array}{l}\text { Household } \\
\text { Children }\end{array}$ & $\begin{array}{l}\text { Pearson's r } \\
\text { Sig. (2- } \\
\text { tailed) } \\
\mathrm{N} \\
\end{array}$ & $\begin{array}{r}.104^{* *} \\
.000 \\
10199 \\
\end{array}$ & $\begin{array}{r}.020^{*} \\
.013 \\
14801 \\
\end{array}$ & $\begin{array}{r}-.052^{* \star} \\
.000 \\
20684 \\
\end{array}$ & $\begin{array}{r}-.098^{* *} \\
.000 \\
12333 \\
\end{array}$ & $\begin{array}{r}1 \\
20684 \\
\end{array}$ & \\
\hline $\begin{array}{l}\text { Income } \\
\text { Distribution }\end{array}$ & $\begin{array}{l}\text { Pearson's r } \\
\text { Sig. (2- } \\
\text { tailed) } \\
\text { N }\end{array}$ & $\begin{array}{r}-.278^{* \star} \\
.000 \\
9513\end{array}$ & $\begin{array}{r}.309^{* *} \\
.000 \\
16593\end{array}$ & $\begin{array}{r}.159^{* *} \\
.000 \\
16593\end{array}$ & $\begin{array}{r}.335^{* *} \\
.000 \\
14049\end{array}$ & $\begin{array}{r}-.124^{* *} \\
.000 \\
13646\end{array}$ & $\begin{array}{r}1 \\
16593\end{array}$ \\
\hline
\end{tabular}

**. Correlation is significant at the 0.01 level (2-tailed).

${ }^{*}$. Correlation is significant at the 0.05 level (2-tailed). 
FIGURE 1: Path Diagram for Moved for Family/Spouse



Aboriginal Peoples Survey, $2012 * * \mathrm{p}<.01 ;{ }^{*} \mathrm{p}<.05$

Decomposition Effects for Moving for Family/Spouse:

For the model in Figure 1, the total effect of age on moving for family/spouse is as follows:

Direct effect: 0.114

Indirect effect: (a) through children in household $(0.054 \mathrm{x}-0.008)=-0.00043$

(b) through children in household and income $(0.054 \times-0.124 \times 0.117)=-0.00078$

(c) through income $(0.182 \times 0.117)=0.02129$

Total effect is the sum of the direct effect and indirect effects:

Total effect $(0.114)+(-0.00043-0.00078+0.02129)=(0.114)+(0.020)=\mathbf{0 . 1 3 4}$

For the model in Figure 1, the total effect of sex on moving for family/spouse is as follows:

Direct effect: 0.033

Indirect effect: (a) through children in household $(-0.110 \mathrm{x}-0.008)=0.00088$

(b) through children in household and income $(-0.110 \times-0.124 \times 0.117)=0.00160$ 
(c) through income $(0.232 \times 0.117)=0.02714$

Total effect is the sum of the direct effect and indirect effects:

Total effect $(0.033)+(0.00088+0.00160+0.02714)=(0.114)+(0.030)=\mathbf{0 . 1 4 4}$

For the model in Figure 1, the total effect of education on moving for family/spouse is as follows:

Direct effect: 0.047

Indirect effect: (a) through children in household $(-0.107 \mathrm{x}-0.008)=0.00086$

(b) through children in household and income $(-0.107 \times-0.124 \times 0.117)=0.00155$

(c) through income $(0.355 \times 0.117)=0.04153$

Total effect is the sum of the direct effect and indirect effects:

Total effect $(0.047)+(0.00086+0.00155+0.04153)=(0.047)+(0.044)=\mathbf{0 . 0 9 1}$

FIGURE 2: Path Diagram for Moved for Work

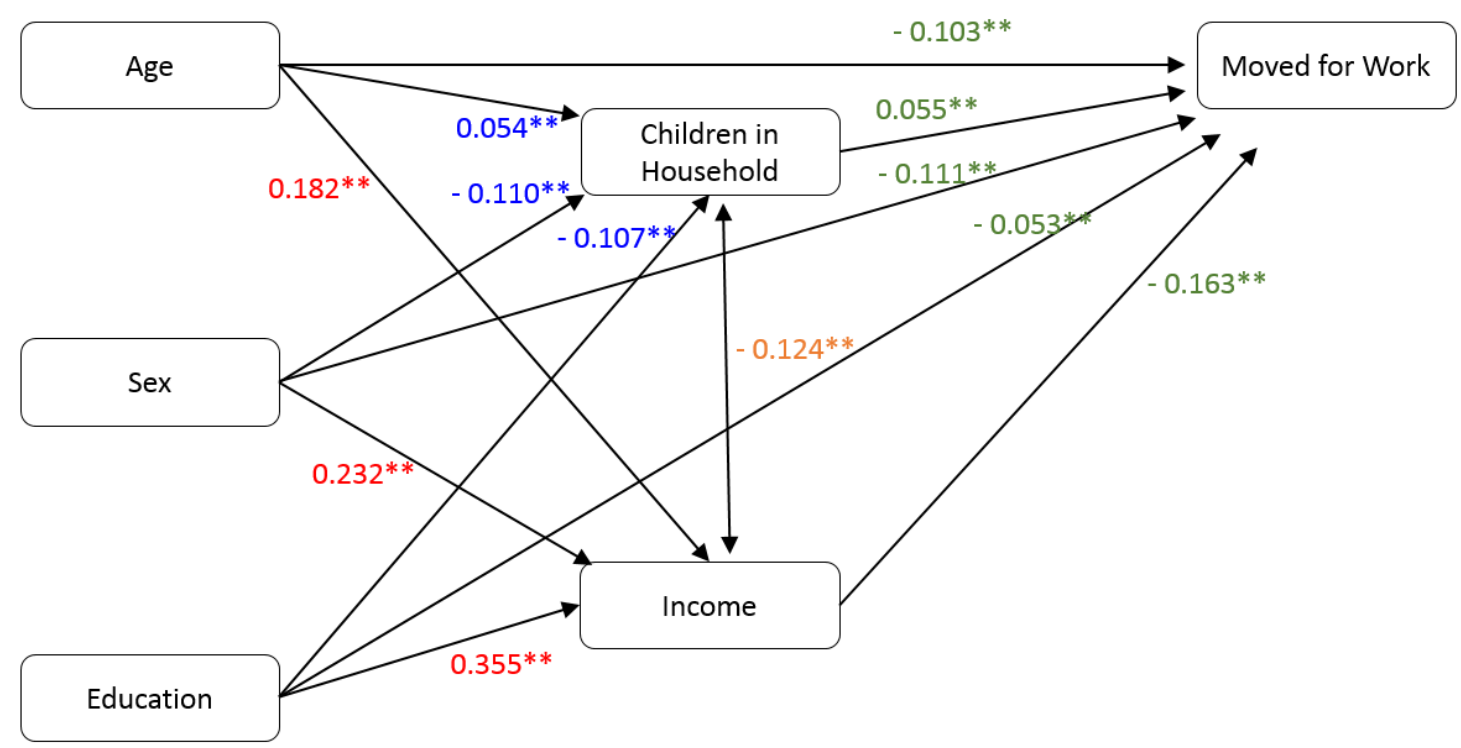

Aboriginal Peoples Survey, $2012 * * p<.01 ;{ }^{*} p<.05$ 
Decomposition Effects for Moved for Work:

For the model in Figure 2, the total effect of age on moving for work is as follows:

Direct effect: -0.103

Indirect effect: (a) through children in household $(0.054 \times 0.055)=0.00297$

(b) through children in household and income $(0.054 \times-0.124 \times-0.163)=0.00109$

(c) through income $(0.182 \times-0.163)=-0.02967$

Total effect is the sum of the direct effect and indirect effects:

Total effect $(-0.103)+(0.00297+0.00109-0.02967)=(-0.103)+(-0.026)=\mathbf{- 0 . 1 2 9}$

For the model in Figure 2, the total effect of sex on moving for work is as follows:

Direct effect: -0.111

Indirect effect: (a) through children in household $(-0.110 \times 0.055)=-0.00605$

(b) through children in household and income $(-0.110 \times-0.124 \times-0.163)=-0.00222$

(c) through income $(0.232 \times-0.163)=0.03782$

Total effect is the sum of the direct effect and indirect effects:

Total effect $(-0.111)+(-0.00605-0.00222+0.03782)=(-0.111)+(0.030)=\mathbf{- 0 . 0 8 1}$

For the model in Figure 2, the total effect of education on moving for work is as follows:

Direct effect: -0.053

Indirect effect: (a) through children in household $(-0.107 \times 0.055)=-0.00589$

(b) through children in household and income $(-0.107 \mathrm{x}-0.124 \mathrm{x}-0.163)=-0.00216$.

(c) through income $(0.355 \times-0.163)=-0.05787$

Total effect is the sum of the direct effect and indirect effects:

Total effect $(-0.053)+(-0.00589-0.00216-0.05787)=(-0.053)+(-0.066)=-\mathbf{0 . 1 1 9}$ 
TABLE 3: Regression Coefficients

\begin{tabular}{|c|c|c|c|c|c|c|c|c|}
\hline & & \multicolumn{2}{|c|}{$\begin{array}{c}\text { Unstandardized } \\
\text { Coefficients }\end{array}$} & \multirow{2}{*}{$\begin{array}{c}\text { Standardized } \\
\text { Coefficients } \\
\text { Beta } \\
\end{array}$} & \multirow[b]{2}{*}{$\mathrm{t}$} & \multirow[b]{2}{*}{ Sig. } & \multicolumn{2}{|c|}{$\begin{array}{c}\text { Collinearity } \\
\text { Statistics }\end{array}$} \\
\hline \multicolumn{2}{|c|}{ Model 1} & B & $\begin{array}{l}\text { Std. } \\
\text { Error }\end{array}$ & & & & Tolerance & VIF \\
\hline \multirow[t]{6}{*}{1} & (Constant) & 1.319 & .025 & & 52.488 & .000 & & \\
\hline & Age Recoded & .043 & .005 & .114 & 9.340 & .000 & .962 & 1.039 \\
\hline & Sex Recoded & .032 & .012 & .033 & 2.578 & .010 & .890 & 1.124 \\
\hline & $\begin{array}{l}\text { Highest Education } \\
\text { Level Attained }\end{array}$ & .016 & .004 & .047 & 3.605 & .000 & .853 & 1.173 \\
\hline & $\begin{array}{l}\text { Household } \\
\text { Children }\end{array}$ & -.005 & .007 & -.008 & -.696 & .487 & .959 & 1.043 \\
\hline & $\begin{array}{l}\text { Income } \\
\text { Distribution }\end{array}$ & .069 & .008 & .117 & 8.592 & .000 & .769 & 1.301 \\
\hline
\end{tabular}

a. Dependent Variable: Moved for Family/Spouse

TABLE 4: Regression Coefficients

\begin{tabular}{|c|c|c|c|c|c|c|c|c|}
\hline \multirow{2}{*}{\multicolumn{2}{|c|}{ Model 2}} & \multicolumn{2}{|c|}{$\begin{array}{c}\text { Unstandardized } \\
\text { Coefficients } \\
\end{array}$} & \multirow{2}{*}{$\begin{array}{c}\text { Standardized } \\
\text { Coefficients } \\
\text { Beta }\end{array}$} & \multirow[b]{2}{*}{$\mathrm{t}$} & \multirow[b]{2}{*}{ Sig. } & \multicolumn{2}{|c|}{$\begin{array}{c}\text { Collinearity } \\
\text { Statistics }\end{array}$} \\
\hline & & B & Error & & & & Tolerance & VIF \\
\hline \multirow[t]{6}{*}{1} & (Constant) & 2.011 & .024 & & 84.698 & .000 & & \\
\hline & Age Recoded & -.037 & .004 & -.103 & -8.663 & .000 & .962 & 1.039 \\
\hline & Sex Recoded & -.104 & .012 & -.111 & -8.925 & .000 & .890 & 1.124 \\
\hline & $\begin{array}{l}\text { Highest Education } \\
\text { Level Attained }\end{array}$ & -.018 & .004 & -.053 & -4.165 & .000 & .853 & 1.173 \\
\hline & $\begin{array}{l}\text { Household } \\
\text { Children }\end{array}$ & .032 & .007 & .055 & 4.602 & .000 & .959 & 1.043 \\
\hline & $\begin{array}{l}\text { Income } \\
\text { Distribution }\end{array}$ & -.093 & .008 & -.163 & 12.238 & .000 & .769 & 1.301 \\
\hline
\end{tabular}

a. Dependent Variable: Moved for Work 
The results of Table 2 "moved for family" coefficients all have a significance (p) value below an alpha level of 0.01. It was shown that age, sex, education level, and income were significant variables to consider regarding mobility for family/spouse. The exception is in regards to households with children, but this exception was not found to be significant. The collinearity diagnostics for the regressions indicate a low Variance Inflation Factor (VIF) (ranging from 1.039 and 1.301) and a moderate level of tolerance (ranging from 0.769 to 0.962). The Eigenvalues of these variables were generally low (0.1 to 0.5$)$, with income and children in the household consistently having the lowest values of all five variables. As with the VIF, the regressions that were conducted with these two variables as independent variables also produced a minimal change in the Eigenvalue.

\section{Discussion}

This analysis supports previous research findings that have suggested that there are, indeed, a number of interrelated socioeconomic factors that may influence a person's decision to move. For example, Clatworthy and Norris (2007) found that both family and the availability of adequate housing were key factors in the decision to move in general. Furthermore, it appears that seeking higher levels of education was the main reason for leaving reserve communities, while employment was the most frequent reason for moving within urban areas (Clatworthy and Norris 2007).

Previous research studies have shown that the Aboriginal population on the whole tends to be a highly mobile group, and the results of this study further demonstrate that there are significant demographic and socioeconomic differences in mobility patterns (Clatworthy 2008; Siggner and Costa 2005; Hull 2006; Quinless 2009). In particular, one of the major findings in this study indicates that there is a strong inverse relationship between age and mobility levels; it was observed that the frequency of residential mobility tends to decrease as individuals get older.

When we review the proposed hypotheses of this analysis, we can conclude the following: it was proposed that a person who is older will move less frequently when compared to someone who is younger. This was only evident in the total effect of age on mobility for work; it did not appear in mobility for family/spouse. Here, there was indication that as one gets older, the decision to move based on family/spouse becomes a more important consideration. The main reasons attributed to higher levels of mobility that have been cited in the literature are related to those individuals who relocate to large urban centres in search of employment and educational opportunities. However, what often happens once they arrive is that these individuals and their families end up living in poor-quality, unaffordable housing in declining inner-city neighbourhoods. A shortage of housing, discrimination by landlords, lack of information on housing availability, inadequate/ substandard housing, and unaffordable costs then contribute further to Aboriginal people's mobility, even after they have arrived in the city. In general, it has been found that low income levels and lack of savings and financial support, as well as a lack of lowincome rental housing, all contribute to housing issues, which in turn result in increased levels of residential mobility within the urban centre. 
It was also proposed that higher levels of income would inversely affect an individual's mobility. This means that a person who has a higher income will not move as often as someone who does not. The path diagram indicates that the direct effect of income on mobility for family points to a positive relationship. However, the results in fact showed that income was inversely related to mobility for work. It appears that higher income enables the freedom to move for family/spouse at the same time as enabling the freedom to remain in one place.

It was further proposed that higher levels of education would be positively related to an individual's level of mobility. It was found in this analysis that higher levels of education have varying effects on the decision to move. There is a positive effect of a higher level of education on moving for family/spouse, which makes sense in Aboriginal cultures, as a higher level of education might encourage one to learn more about one's culture and perhaps spend more time with relatives in order to do so. With the second model, our hypothesis was demonstrated at a higher level of education and did indeed result in a lower level of mobility for work.

While it was proposed that females will move more frequently than males, the actual effect of sex on mobility for either model could not be concluded from the analysis; however, it was proposed that having children within a household is a significant predictor of mobility. Having more children in the household had a very minimal effect on moving for either family or work when compared to having fewer children. Our suggestion is that future cycles of the Aboriginal Peoples Survey add more questions to determine adequately the number of children who generally reside in a household, and that it and that it draw this information from males and females, not simply from female respondents.

\section{Conclusion}

The main purpose of this paper was to examine the effects of various socio-economic factors such as age, sex, education level, family composition (expressed by the number of children in household) and total personal income on the mobility patterns of Aboriginal people living off reserve in Canada. Two separate path analyses were conducted to critically evaluate the decomposition effects that these variables have on mobility and have shown that age is inversely related to mobility, meaning younger people move more frequently. However, contrary to other studies this research analysis shows that age becomes less significant when we consider that people with higher levels of education are indeed more mobile but this has an intervening effect through income and family composition.

This analysis makes contributions to the mobility literature by critically examining the two most commonly reported reasons for moving among the Aboriginal community: 1) for family/spouse and 2) for work which previous studies have overlooked. Our first model showed that an increase in age resulted in an increase in mobility for family/spouse. This finding supports our previous claim that relationships and family are an important component to Aboriginal culture, indicating that as we get older, there is a greater likelihood that we will move for or to our family. It was further observed that an increase in education resulted in an increase in mobility for family/spouse, suggesting that education 
levels do affect Aboriginal people and leads to more frequent moves for family/spouse. Meanwhile, in the second model, we observed that an increase in age also resulted in a decrease in mobility for work. The second model also showed that the higher the level of education, the less people move to look for work. This also makes sense as individuals with higher levels of education would most often have higher level and more stable jobs, limiting the need to move as frequently in search of work. While age was shown to be a significant predictor of higher levels of mobility, the results in this study also showed moving for family and work are important social factors in predicting higher mobility levels. The results of the path analysis indicate that sex and age are much higher predictors of moving for one's family or spouse while age and education are more important than one's sex in moving to seek work. Overall, age appears to be the most accurate predictor of mobility. The dichotomy of results in this data analysis could be an indication of the emerging formation of an Aboriginal urban middle class (Aman 2008) and these findings point to further research directions. Overall, the results of this research study contribute to the nascent literature on the mobility patterns of Aboriginal people living of reserve across Canada and represent one of the few studies that have explored the intervening effects of mobility patterns in the context of education, income and family composition. This would suggest that there is indeed an impact of Family Relationships and Work on Mobility Patterns of Aboriginal People Living in Urban Centres across Canada. Continued research that explores this complex relationship is key to understanding urban Aboriginal movers and shaping effective policy in terms of a variety of social service and health care programs and services in urban settings. 


\section{Bibliography}

Aman, C. 2008. "Aboriginal Students and School Mobility in British Columbia Public Schools." Alberta Journal of Educational Research 54(4): 365-78.

Ambert, Anne-Marie. 2006. "One Parent Families: Characteristics, Causes, Consequences, and Issues." Contemporary Family Trends. Ottawa: The Vanier Institute of the Family. http://www.vifamily.ca/library/cft/oneparent.pdf.

Ark Research Associates. 1996. The Housing Conditions of Aboriginal Peoples in Canada. Prepared for Social and Economic Policy and Research, Canada Mortgage and Housing Corporation.

Buglear, John. 2014. Practical Statistics: A Handbook for Business Projects. London: Kogan Page.

Caledon Institute of Social Policy. 2006. The Choice in Child Care Allowance: What You See Is Not What You Get. Caledon Commentary, January 2006. http://www.caledoninst. org/Publications/PDF/564ENG.pdf.

Canadian Mortgage and Housing Corporation. 1997. Housing Needs of Off-Reserve Aboriginal Lone Parents. Research and Development Highlights. Socio-economic Series 34.

http://www.cmhc-schl.gc.ca/publications/en/rh-pr/socio/socio034.pdf.

Catherine Palmer and Associates, Inc. 2007. Aboriginal Housing in British Columbia: Needs and Capacity Assessment. Victoria, B.C.: BC Office of Housing and Construction Standards.

Clatworthy Stewart J. 1996. The Migration and Mobility Patterns of Canada's Aboriginal Population. Report prepared for the Royal Commission on Aboriginal Peoples. Ottawa: Canada Mortgage and Housing Corporation and the Royal Commission on Aboriginal Peoples.

Clatworthy Stewart J., and Mary Jane Norris. 2007. "Aboriginal Mobility and Migration: Trends, Recent Patterns, and Implications, 1971-2001." In Aboriginal Policy Research, Volume IV: Moving Forward, Making a Difference, edited by Jerry P. White, Susan Wingert, Dan Beavon, and Paul Maxim. Toronto: Thompson Education Publishing Inc.

Cloutier, Elisabeth, and Eric Langlet. 2014. Aboriginal Peoples' Survey, 2012: Concepts and Methods Guide, February 2014. Catalogue no.89-653-X-No.002 ISBN 978-1-10022738-2. Ottawa: Statistics Canada. 
Chalifoux, Thelma, and Janis G. Johnson. 2003. Urban Aboriginal Youth: An Action Plan for Change. The Standing Senate Committee on Aboriginal Peoples' Final Report. http://www.parl.gc.ca/content/sen/committee/372/abor/rep/repfinoct03-e.pdf.

Foster, J., E. Barkus, and C. Yavorsky. 2006. "Path Analysis." In Understanding and Using Advanced Statistics, 89-103. London: SAGE Publications Ltd.

Guimond, Eric, and Norbert Robitaille. 2008. "When Teenage Girls have Children: Trends and Consequences" Horizons: Hope and Heartbreak: Aboriginal Youth and Canada's Future. Ottawa: Government of Canada Policy Research Initiative, Volume 10 Number 1, pages 40-51.

Hull, Jeremy. 2001. Aboriginal Single Mothers in Canada, 1996: A Statistical Profile. Ottawa: Indian and Northern Affairs Canada.

http://www.ainc-inac.gc.ca/ai/rs/pubs/re/smt/smt-eng.pdf.

- - - 2006. Aboriginal Women: A Profile from the 2001 Census. Ottawa: Women's Issues and Gender Equality Directorate Indian and Northern Affairs Canada.

Institute of Urban Studies. 2004. First Nations/Métis/Inuit Mobility Study. Final Report. In collaboration with Assembly of Manitoba Chiefs, Manitoba Métis Federation. Winnipeg: University of Winnipeg Institute of Urban Studies.

Julien, Mark, Barry Wright, and Deborah M. Zinni. 2010. "Stories from the Circle: Leadership Lessons Learned from Aboriginal Leaders.” The Leadership Quarterly 21(1): 114-26.

Maxim, Paul S., Carl Keane, and Jerry White. 2003. "Urban Residential Patterns of Aboriginal People in Canada." In Newhouse and Peters, Not Strangers in These Parts, 79-92.

Mendelson Michael 2004. Aboriginal People in Canada's Labour Market: Work and Unemployment, Today and Tomorrow. Ottawa: The Caledon Institute of Social Policy.

Mochama, Agnes. 2001. "Residential Mobility of the Urban Poor: A Study of Female-Headed Single Parent Aboriginal Households in Winnipeg." Master's thesis, University of Winnipeg. http://mspace.lib.umanitoba.ca/bitstream/1993/2570/1/MQ62800.pdf.

Newhouse, David, and Evelyn Peters, eds. 2001. Not Strangers in These Parts: Urban Aboriginal Peoples. Ottawa: Indian and Northern Affairs Canada, Policy Research Initiative. http://policyresearch.gc.ca/doclib/AboriginalBook_e.pdf. 
Norris, Mary Jane, and Stewart Clatworthy. 2003. "Aboriginal Mobility and Migration Within Urban Canada: Outcomes, Factors and Implications." In Newhouse and Peters, Not Strangers in these Parts, 51-78.

Ning, Ashley. 2013. Mobilities of Aboriginal Youth: Exploring the Impact on Health and Social Support Through Photovoice. PhD diss., University of Toronto.

Quinless, Jacqueline. 2009. “Urban Aboriginal Population: A Statistical Profile of Aboriginal People Residing in the City of Edmonton in 2006." Prepared for the Aboriginal Relations Office and the Office of the Deputy Manager, City of Edmonton.

- - - 2013. "First Nations Teenaged Lone Mothers in Canada: Understanding

Diverse Realities and the Importance of Networks of Care." International Indigenous Policy 4(1): 1-15.

Rea, Willa, Jennifer Yuen, John Engeland, and Roberto Figueroa. 2008. “The Dynamics of Housing Affordability.” Perspectives 15-26. Statistics Canada Catalogue no. 75-001X. Ottawa.

Ristock, Janice, Art Zoccole, and Lisa Passante. 2010. Aboriginal Two Spirit and LGBTQ Migration, Mobility, and Health Research Project. Accessed January 15, 2016. http:// www.2spirits.com/PDFolder/MMHReport.pdf.

Rohs, F. Richard, and Christine A. Langone. 1993. "Assessing Leadership and ProblemSolving Skills and their Impacts in the Community." Evaluation Review 17: 109-115.

Royal Commission on Aboriginal Peoples. 1993. Aboriginal Peoples in Urban Centres: Report of the National Round Table on Aboriginal Urban Issues.

Siggner, Andrew, and Rosalinda Costa. 2005. "Aboriginal Conditions in Census Metropolitan Areas, 1981-2001." Trends and Conditions in Census Metropolitan Areas. Ottawa: Statistics Canada.

http://www.statcan.gc.ca/pub/89-613-m/89-613-m2005008-eng.pdf.

Snyder, Marcie, and Kathi Wilson. 2012. "Urban Aboriginal Mobility in Canada: Examining the Association with Health Care Utilization." Social Science \& Medicine 75(12): $2420-24$.

Spector, Paul. 1997. Job Satisfaction: Application, Assessment, Causes and Consequences. California: Sage. 
Statistics Canada. 2012. “Aboriginal Peoples Survey (APS)” Accessed January 25, 2016. http://www23.statcan.gc.ca/imdb/p2SV. $\mathrm{pl}$ ? Function $=$ getSurvey $\&$ SDDS $=3250 \&$ lang $=\mathrm{en} \& \mathrm{db}=\mathrm{imdb} \& \mathrm{adm}=8 \& \mathrm{dis}=2$.

——_. 2015. "National Aboriginal Day ... By the Numbers." Accessed January 15, 2016. http://www.statcan.gc.ca/eng/dai/smr08/2015/smr08_202_2015. 